\title{
PROBATIVE VALUE OF MEDICAL EVIDENCE TOWARDS ESTABLISHING ULTIMATE PROBANDUM AND PENULTIMATE PROBANDA IN A COURT ROOM.
}

\author{
Induwara Goonerathne \\ Department of Forensic Medicine, Faculty of Medicine, University of Peradeniya
}

This article attempts to re-emphasize the probative value of medical evidence especially in a criminal court of adversarial nature, towards establishing the ultimate probandum. Further it is intended in this paper to identify a few issues pertaining to the effective use of medical evidence in the Sri Lankan judicial system for this purpose (in proof of a probandum) and propose remedial alternatives with an intention to constructively improve the system.

The main object and purpose of a criminal legal proceeding in Sri Lanka is to establish the propositions of the prosecution beyond a reasonable doubt in an attempt to administer justice. In this process, evidence is presented in form of physical or as testimony of witnesses. The accused who is presumed to be innocent until proven otherwise is provided opportunity in the law to defend himself against postulated propositions through, inter alia, rebuttal, denial, rival counter explanation, or using a legal defense argument.

In the court room, when the evidence is presented it is assumed and reasonably expected to analyze the evidence in terms of factual or material connotations (factual analysis) as well as performing a legal analysis. The common methods of legal reasoning used are inductive, deductive, abductive approaches or a combination. Very commonly logic is used in proving or disproving a proposition. A thorough understanding of logical reasoning and their limits are fundamental legal skills. Further, understanding the nature and application of law, articulation of facts, law and precedence, problem solving skills, appreciating and formulating arguments, coherence, making rational inferences are key components in proof of an ultimate probanda.

In proof of propositions and material facts, Wigmore has proposed a chart method ${ }^{1}$ and construction of a key list which can be used in solving a criminal issue. This approach has been accepted to be logical, rational, coherent and allow inferences to be made effectively, if properly constructed. Rationalist tradition prevails in the anglo-american tradition of proof. It is reflected in the English law based legal system in Sri Lanka and unarguably in the western medico-legal practice. In this tradition, the inferential characteristics are relevance, credibility and probative force of evidence.

For a prosecution attorney, in order to establish his case a key list and a probable proposition chart is relevant. Analyzing all relevant propositions and hypothesis, the prosecution attorney can design their lines of arguments and the by which he would present his evidence. Similarly the defense can form their key list, proposition chart in order to establish the position of the defense.

Medical evidence can play a pivotal role in a criminal case. They can be used to either establish or reject a hypothesis or a proposition in a legal chart. It is up to the legal expert concerned to utilize and apply factual medical evidence and medical opinions to establish or nullify postulated hypotheses in order to ultimately reach its ultimate probandum. The probative values of medical evidence can be different depending on the case. In some legal cases medical evidence may not be used at all to establish or nullify penultimate probanda or ultimate probanda. The use of probative value of medical evidence can vary depending on the context of the case as well as on the experience of the lawyer. One lawyer may utilize medical evidence with a high probative value supported by other evidence while another lawyer may not use medical evidence for his propositions.

One main issue legal experts face is their lack of understanding of medicine. On the other hand medical practitioners having inadequate understanding of the law and legal requirement may produce evidence in such a way that the legal expert will be reluctant to utilize but depend on other available evidence to achieve legal aims which makes medical evidence redundant.

The law schools in Sri Lanka do not teach an essential component in evidence law which is "proof". Therefore the young lawyers have to rely on their seniors to learn aspects of "proof" through apprenticeship. The senior lawyers and judges too 
learn important aspects of proof and logics that are required for legal reasoning through continuous education, experience and law research. It may be pertinent that the Sri Lankan Law schools attempt to introduce "proof" component in evidence law which will benefit not only the lawyer and the judge but also the society and the system as a whole. Similarly the forensic training in Sri Lanka too does not involve formal theoretical teaching of "proof" and logic part which is an essential component in establishing the relevant scientific hypothesis concerning the 'death' or 'injury'. The experts learn it through experience, peer learning and learning through apprenticeship. It would have been better if both fraternities are formally taught about principles of proof that applies to science (for scientists) and to legal reasoning (for lawyers) so that their work becomes more logical coherent and outcome based. Forensic practitioners be it pathologists, anthropologists, odontologists or forensic scientists in their day to day work engage in proof of a generated hypothesis. Therefore not only in the work of a court of law but also in the work of a forensic expert, foundations of logic and principles of proof are relevant.

Taking an example outlined below, it can be illustrated as to how useful the principles of proof is to court as well as in a forensic investigation. I will be using a "Wigmore chart method"1 supported by an already established key list to illustrate as to how proof of a proposition can be established for practical purposes. In a hypothetical case where Perera is charged with rape of Rani, the ultimate probandum in accordance to our penal law would be that " Perera raped Rani on 01.01.2012 around 9 pm." The material facts and the penultimate probanda would be that "perera had vaginal sexual intercourse with Rani on 01.01.2012 around 9 pm, there was a penile penetration and that this sexual intercourse in question occurred without the consent of Rani.

In establishing the hypothesis that there was vaginal intercourse two types of evidence can be useful. One would be scientific evidence and the other would be testimonies of the victim or witnesses. Those statements and certain behaviors of Rani, subsequent to the alleged incident can be taken into account as long as they are admissible without prejudice to hearsay or relevance. One of the prime scientific evidence of vaginal penetration would be vaginal injuries including hymenal injuries. The hypotheses such as "there are no vaginal injuries" and " that the injuries can be caused by methods other than penile penetration" or that "the injuries are not compatible with the alleged time or history" or that they are self inflicted and fabricated" can be brought up as defenses or rival explanations. These postulations can reduce the probative value of each piece of evidence in this case the presence or absence of vaginal injuries but will not nullify/negate the material fact totally. On the other hand the presence of semen in the vagina in the first instance is reliable evidence of a sexual act. However the propositions that semen can enter vagina via ways other than by penile penetration such as manual deposition, foreplay etc are relevant propositions. However the presence of Perera's DNA in the isolated semen in the vaginal swab from Rani will provide a strong correlation between Perara's involvement with Rani sexually. However this will not establish non consensual vaginal intercourse beyond a doubt although this evidence is with a high degree of probative value. In proof of "non consent" other evidence such as evidence of violence, pattern of injuries, eye witnesses, testamentary of victims are relevant to make alternative or supportive probanda. Establishing Perera's alibi is an important defense.

The establishment of "rape" in legal sense is multi factorial and will have to establish all penultimate probanda beyond a doubt (using intermediate probanda) in order to establish the ultimate probanda beyond a reasonable doubt to succeed.

This illustration helps to understand the use of Wigmorian approach ${ }^{2}$ both to establish a medical hypothesis in the forensic laboratory as well as to establish a legal hypothesis in a court of law. Part of a Basic Wigmore chart is below to illustrate the proof of ultimate and penultimate probanda in relation to the above illustration. 


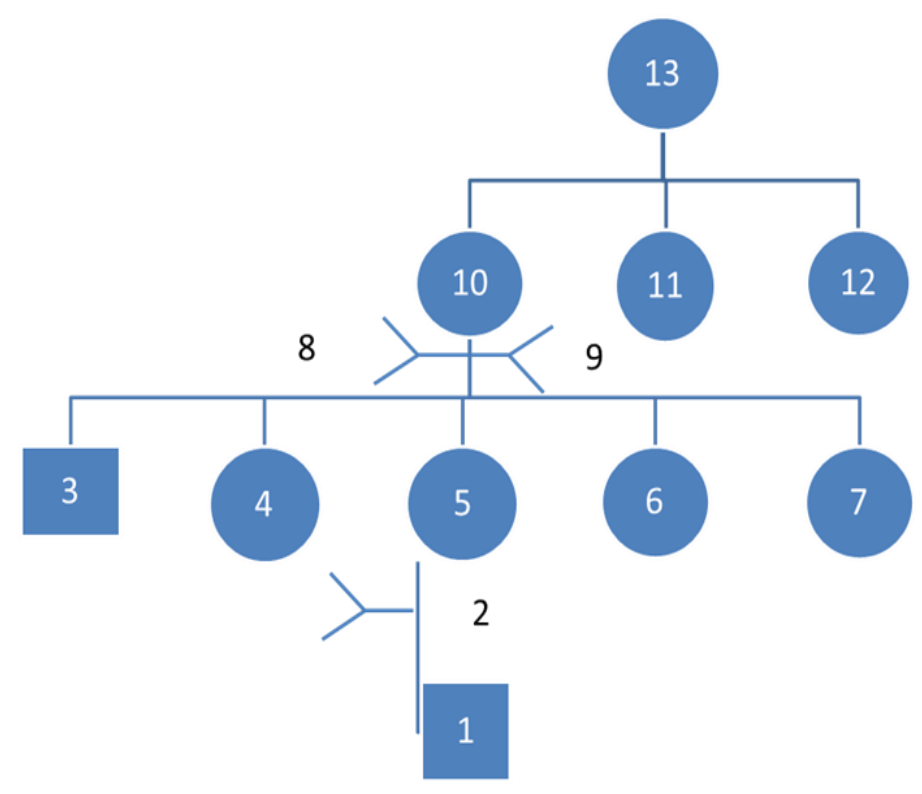

1. A testimony of a witness who heard Rani cry for help

2. Rani had a money dispute with Perera

3. Rani's statement

4. Presence of male pubic hair in Rani's genital area.

5. DNA isolated from Rani's vaginal swab

6. Recent injuries to Rani's hymen and vaginal tract

7. DNA isolated from Rani's vaginal swab belongs to Perera

8. Perera had a sexual relationship with Rani for some time

9. Perera was visiting a patient in a far away hospital on 01.01.2012 evening.

10. Perera had a sexual intercourse with Rani on 01.01.2012 at around $9 \mathrm{pm}$

11. Perera's penis penetrated into Rani's vagina

12. The intercourse Perera had with Rani on 01.01 .2012 at around $9 \mathrm{pm}$ is without her consent

It must be noted that this is a very basic presentation of a Wigmorian chart merely for illustration purposes. There can be several different interconnected segments with intermediate probanda and items of evidence connecting to material facts and then to penultimate probanda in a Wigmore chart in a real case scenario with propositions for and against prosecution which ${ }^{3}$ can look complex but provides a logical coherent line of argument in order to prove the position of the prosecution or the defense.

\section{REFERENCES}

1. Anderson T, Shum D, Twining W. Analysis of Evidence, Cambridge University Press. 2005

2. Murphy, P. Evidence Proof and Facts Oxford University press. 2003

3. Filkelstein M O, Fairley W. B.A (1070). A Bayesian approach to Identification Evidence.vol 83 No 3 PP489-510.

13. Perera committed the offense of rape. 